\title{
Trace Determination of Superoxide Dismutase by Anodic Scan Pulse Voltammetry
}

\author{
Seiki Yamaguchi*, Osamu TAkemura**, Tokuji Ikeda** and Mitsugi Senda** \\ *Department of Chemistry, Osaka Medical College, Sawaragi-cho, Takatsuki, Osaka 569, Japan \\ ** Department of Agricultural Chemistry, Faculty of Agriculture, Kyoto University, Kyoto 606, Japan
}

\begin{abstract}
This assay for superoxide dismutase (SOD) involves two electrode reactions: 1) the generation of a substrate $\left(\mathrm{O}_{2}{ }^{-}\right)$ by a one-electron reduction of dissolved oxygen at a constant potential of $-1.0 \mathrm{~V}$ in a pH 11.0 borate-carbonate buffer solution containing $2 \times 10^{-4} \mathrm{~mol} / \mathrm{I}$ EDTA and $2.4 \times 10^{-4} \mathrm{~mol} / \mathrm{l}$ triphenylphosphine oxide, and 2) the detection of a residual substrate, which results from an SOD-catalyzed reaction at $-0.1 \mathrm{~V}$ by one-electron oxidation with anodic scan pulse voltammetry. By the use of a hanging mercury drop electrode (a static mercury drop electrode) and with a sequence-control technique, these reactions are so strictly controlled that an SOD as low as $10^{-12} \mathrm{~mol} / \mathrm{I}$ can be determined within a short time $(<30 \mathrm{~s})$ under automatic operation.
\end{abstract}

Keywords Superoxide dismutase, anodic scan pulse voltammetry, sequence-controlled polarography

Superoxide dismutases (SODs), which catalyze the dismutation of $\mathrm{O}_{2}^{-}$according to

$$
2 \mathrm{O}_{2}^{-} \longrightarrow \mathrm{O}_{2}+\mathrm{H}_{2} \mathrm{O}_{2} \text {, }
$$

and protect living organisms from damage formed in the reduction of molecular oxygen to $\mathrm{H}_{2} \mathrm{O}$, are currently of interest regarding many biochemical systems. ${ }^{1-4}$

Assays for SOD can be classified into two groups, according to the methods for the formation and detection of the substrate $\left(\mathrm{O}_{2}^{-}\right)$. The first method, which has been used in many biochemical studies, can be called an indirect assay. ${ }^{2,5-9}$ In this method $\mathrm{O}_{2}{ }^{-}$is generated enzymatically and reacts with appropriate indicators, such as cytochrome $c$ and tetrazolium salts, so that the concentration of SOD can be calculated from the change in the concentration of these indicators. In general, indirect assays are useful from $10^{-9}$ to $10^{-10} \mathrm{~mol} / 1$ of SOD concentration. ${ }^{6,8}$ However, these assays are influenced by many interfering effects caused by other systems in biological materials. Furthermore, the complex enzymatic reactions used in these assays are seriously influenced by the impurity of reagents, the reaction time and the $\mathrm{pH}$ of solutions. ${ }^{8-10}$ The second method, the direct assay, is based on the electrochemical generation and detection of $\mathrm{O}_{2}^{-}$at the surface of a mercury electrode in the presence of surface-active substances, such as triphenylphosphine oxide. ${ }^{11-15}$ Contrary to the enzymatic procedures, the generation and detection of an stable substrate can be so precisely regulated at the electrode surface that this assay suggests the possibility of measuring very small amounts of SOD.

With the aid of a sequence control technique, Yamaguchi et al. ${ }^{17}$ have constructed a versatile electroanalytical measuring system, a sequence-controlled polarograph. By this system, both the formation period and the surface area of an indicator electrode are so precisely controlled that numerous electrochemical measurements can be carried out automatically with good reproducibility and with a minimum consumption of mercury.

The behavior of dissolved oxygen and the reaction mechanisms in a direct assay of SOD at the surface of a mercury electrode have already been discussed. ${ }^{13-16}$ In this study we focused on the introduction of a simple and reliable procedure for an assay of trace amounts of SOD, in which a sequence-control technique was combined with pulse-voltammetric techniques, such as anodic scan pulse polarography (ASPP) or potential stepping voltammetry.

\section{Experimental}

\section{Material, reagents and solution}

$\mathrm{Cu}, \mathrm{Zn}$-superoxide dismutase (SOD, EC. 1.15.1.1) from bovine liver was donated by Prof. Asada of Kyoto University. A weighed amount of SOD was dissolved 
in triply distilled water (a stock solution) and the concentration of SOD in the stock solution was measured according to the absorbance at $680 \mathrm{~nm}$ using a molar absorptivity of $237\left(\mathrm{~mol} / \mathrm{l}^{-1} \mathrm{~cm}^{-1} .^{18}\right.$ The specific activity of the SOD was 3547 unit per mg by McCord and Fridovich. ${ }^{5}$ Triphenylphosphine oxide (TPO, Tokyo Kasei Co., Tokyo) and ethylenediamine tetraacetic acid disodium salt (EDTA, Dojin Kagaku Co., Kumamoto) were of reagent grade. An airsaturated borate-carbonate buffer solution $(0.2 \mathrm{~mol} / 1$ (M), pH 11.0) containing $2 \times 10^{-4} \mathrm{M}$ EDTA and $2.4 \times$ $10^{-4} \mathrm{M}$ TPO was used as a basal solution. All other chemicals used were highly pure commercial products (Wako Pure Chemical Ind. Ltd., Osaka).

\section{Apparatus}

The electrochemical system was assembled from four units: an electrode unit in which a static mercury drop electrode (SMDE, Princeton Apply Research Co.) was used as an indicator electrode, a potential-supply and current recording unit, a data-processing unit and a controlling unit. Details concerning the construction and application of this system were reported previously. ${ }^{17}$

All electrochemical measurements were carried out in an $\mathrm{H}$-type glass cell thermostated at $25 \pm 0.1^{\circ} \mathrm{C}$. All potentials were measured against a saturated calomel electrode (SCE).

\section{Measurement}

Two and a half milliliters of a basal solution was transferred into the cell, and an aliquot of the stock solution was syringed into the basal solution manually. The following procedures were performed automatically according to the programmed timing sequence. The test solution was mixed for $15 \mathrm{~s}$ and kept still for $15 \mathrm{~s}$. Just after the birth of a mercury drop, an initial potential $\left(E_{\mathrm{i}}\right.$, usually $\left.-1.0 \mathrm{~V}\right)$ was applied to the electrode for a definite time ( $T_{\mathrm{i}}$, usually $9 \mathrm{~s}$ ), which was followed by a potential scan by ASPP, or more convieniently, stepped by a potential stepping voltammetry into positive direction.

The current due to the oxidation of $\mathrm{O}_{2}^{-}$was measured at $-0.1 \mathrm{~V}$ and was converted to the concentration of SOD.

\section{Results and Discussion}

Typical current-potential curves recorded by ASPP in the absence and presence of $2 \times 10^{-9} \mathrm{M}$ SOD in the basal solution are given in Fig. 1. The decrease in the anodic current height within the potential range -0.3 to $-0.1 \mathrm{~V}$ has been attributed to a partial consumption of $\mathrm{O}_{2}^{-}$by the SOD-catalyzed reaction. In this procedure the generation of $\mathrm{O}_{2}^{-}$at the surface of the SMDE at the potential of $E_{\mathrm{i}}(-0.8 \mathrm{~V}$ to $-1.0 \mathrm{~V})$ for a given period of time $\left(T_{\mathrm{i}}\right)$ is expressed as

$$
\mathrm{O}_{2}+\mathrm{e}^{-} \longrightarrow \mathrm{O}_{2}^{-}
$$

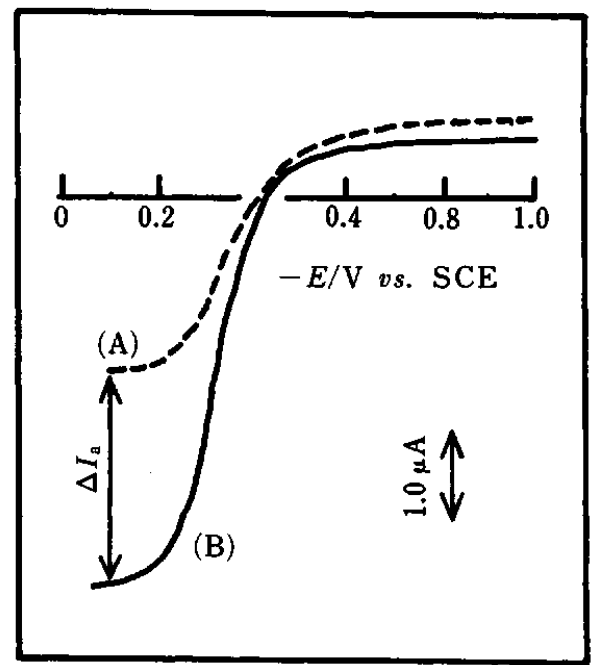

Fig. 1 Anodic scan pulse polarograms at an SMDE. (A),

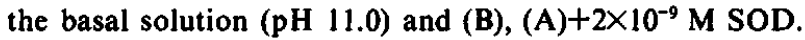
The substrate $\left(\mathrm{O}_{2}^{-}\right)$was generated at the potential of $-1.0 \mathrm{~V}$ for $9 \mathrm{~s}$.

during this reaction time, part of the produced $\mathrm{O}_{2}^{-}$is consumed in the bulk of the solution according to

$$
2 \mathrm{O}_{2}^{-}+2 \mathrm{H}^{+} \longrightarrow \mathrm{O}_{2}+\mathrm{H}_{2} \mathrm{O}_{2}
$$

so that when the potential of SMDE is rapidly scanned or stepped to $-0.1 \mathrm{~V}$, the oxidation current due to the remaining $\mathrm{O}_{2}^{-}$is observed as

$$
\mathrm{O}_{2}^{-}-\mathrm{e}^{-} \longrightarrow \mathrm{O}_{2}
$$

The anodic current based on Eq. (4) can be expressed as

$$
I_{\mathrm{a}}=\kappa\left[\mathrm{O}_{2}^{-}\right]^{\mathrm{o}}
$$

where $\kappa$ is a proportionality constant and $\left[\mathrm{O}_{2}^{-}\right]^{\circ}$ indicates the concentration of $\mathrm{O}_{2}{ }^{-}$in the vicinity of the electrode surface. According to theoretical considerations concerning ASPP15,19, the relationship between $\left[\mathrm{O}_{2}^{-}\right]^{\circ}$ and the concentration of $\mathrm{O}_{2}^{-}$in a solution $\left(\left[\mathrm{O}_{2}\right]^{*}\right)$ is expressed as

$$
\left[D / \pi T_{\mathrm{i}}\right]^{1 / 2}\left[\mathrm{O}_{2}\right]^{*}=\left\{\mu k C_{\text {SOD }}+\left(D / \pi T_{\mathrm{i}}\right)^{1 / 2}\right\}\left[\mathrm{O}_{2}^{-}\right]^{\circ}
$$

where $D$ is the diffusion coefficient of both $\mathrm{O}_{2}$ and $\mathrm{O}_{2}^{-}$ (the equivalent $D$ value for the two species is assumed), $\mu$ is the thickness of the reaction layer in which the SOD-catalyzed reaction occurs, and $k$ is the rate constant of Eq. (3). Substituting Eq. (6) into Eq. (5), we obtain

$$
I_{\mathrm{a}}^{\mathrm{o}} / I_{\mathrm{a}}=1+\left(\pi T_{\mathrm{i}} / D\right)^{1 / 2} \mu k C_{\mathrm{SOD}}
$$

where $I_{\mathrm{a}}^{\circ}$ is the $I_{\mathrm{a}}$ value at $C_{\mathrm{SOD}}=0$, which is given by $I_{\mathrm{a}}^{\circ}=\kappa\left[\mathrm{O}_{2}\right]^{*}$. At various concentrations of SOD and changing the $\mathrm{O}_{2}{ }^{-}$-generation time $\left(T_{i}\right)$, the anodic 


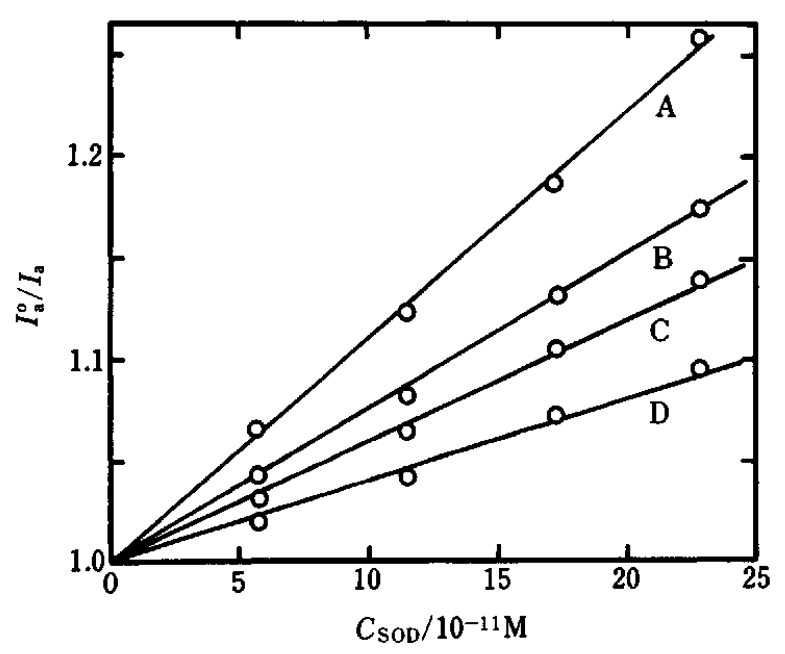

Fig. 2 Plot of $I_{\mathrm{a}}^{\circ} / I_{\mathrm{a}}$ at $-0.1 \mathrm{~V}$ against $C_{\text {sod. }} T_{\mathrm{i}}: \mathrm{A}, 9.0 ; \mathrm{B}$, $5.0 ; \mathrm{C}, 2.8 ; \mathrm{D}, 1.6 \mathrm{~s}$.

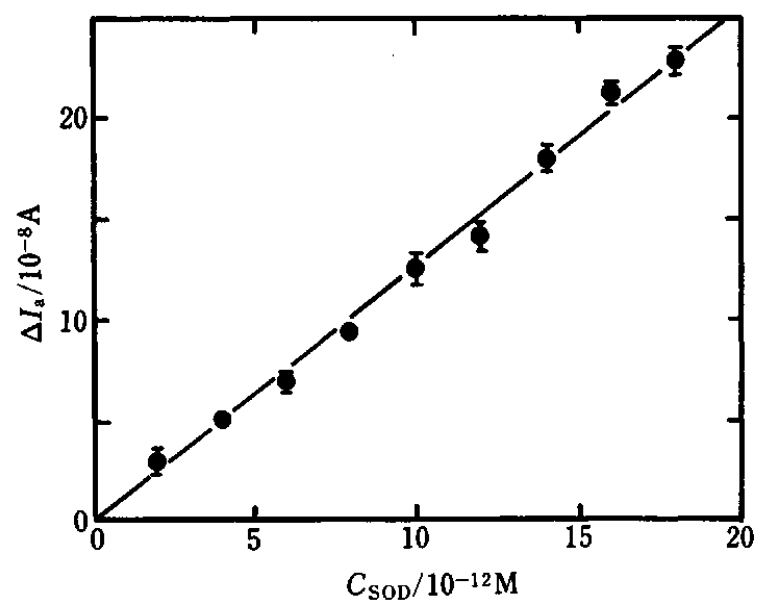

Fig. 3 Plot of $\Delta I_{\mathrm{a}}$ at $-0.1 \mathrm{~V}$ against $C_{\text {SoD }}$ by ASPP.

current was recorded by ASPP. From the oxidation current at $-0.1 \mathrm{~V}$, the ratio of two currents $\left(I_{\mathrm{a}}^{\mathrm{o}} / I_{\mathrm{a}}\right)$ vs. $C_{\text {Son }}$ plots gave straight lines with a vertical intersection of 1.0 (Fig. 2); at constant concentrations of SOD, such as $6 \times 10^{-11}$ and $23 \times 10^{-11} \mathrm{M}$, the ratio $I_{\mathrm{a}}^{\circ} / I_{\mathrm{a}}$ increased linearly with $T_{i}^{1 / 2}$, as predicted by Eq. (7).

From the view point of an SOD assay, Fig. 2 shows that concentrations on the order of $10^{-10}$ to $10^{-11} \mathrm{M}$ can easily be measured by calculating the ratio $\left(I_{\mathrm{a}}^{\circ} / I_{\mathrm{a}}\right)$. At very low concentrations, Eq. (7) can be rewritten as

$$
\begin{aligned}
\Delta I_{\mathrm{a}} & =I_{\mathrm{a}}^{\mathrm{o}}-I_{\mathrm{a}} \\
& =\left(\pi T_{\mathrm{i}} / D\right)^{1 / 2} \mu k I_{\mathrm{a}}^{\circ} C_{\mathrm{SOD}} .
\end{aligned}
$$

Thus, the decrement in $I_{\mathrm{a}}$ is expected to be proportional to $C_{S O D}$. Decrements at $-0.1 \mathrm{~V}$ in ASPP were recorded with a successive addition of an aliquot of the stock solution of SOD to the basal solution and automatic operation. The results are given in Fig. 3. Each point in this figure represents an average value and a maximum deviation. The $\Delta I_{\mathrm{a}}$ value increased linearly with an increase in $C_{\text {SOD }}$ on the order of $10^{-12} \mathrm{M}$ (correlation coefficient of 0.997 ), as predicted by Eq. (8).

The sensitivity of this method is one order of magnitude higher than that of conventional polarography or cyclic voltammetry using catalytic oxygen reduction current ${ }^{11-14}$, and is comparable to that of the spectrophotometric method ${ }^{7}$, which shows the highest sensitivity hitherto reported. This method, which is a direct assay, appears to provide a convenient method for assays of trace amounts of SOD and details in clinical applications will be reported in the near future.

The authors thank Prof. K. Asada and Dr. M. Takahashi of the Research Institute for Food Science, Kyoto University, for their donation of SOD and relevant advice in measuring the specific activity of the enzyme.

\section{References}

1. K. Asada, Seikagaku, 48, 226 (1976).

2. Y. Ohyagi, "Superoxide and Medicine", p. 91, Kyoritu Shuppann, Tokyo, 1981.

3. L. Packer and N. O. Kaplan, ed., "Methods in Enzymology", Vol. 105, p. 22, Academic Press, New York, 1984.

4. Y. Kono, Nippon Nogeikagaku Kaishi, 62, 1112 (1988).

5. J. M. McCord and I. Fridovich, J. Biol. Chem., 244, 6049 (1969).

6. L. Flotte and F. Otting, "Methods in Enzymology", Vol. 105, p. 93, Academic Press, New York, 1984.

7. T. W. Kirby and I. Fridovich, Anal. Biochem., 127, 435 (1982).

8. Y. Ohyagi, Anal. Biochem., 142, 290 (1984).

9. Y. Sun, L. W. Oberley and Y. Li, Clin. Chem., 34, 497 (1988).

10. EMBO Workshop, "Superoxide and Superoxide Dismutase", ed. A. M. Michelson, p. 11, Academic Press, London, 1977.

11. A. Rigo, R. Tomat and G. Rotilio, J. Electroanal. Chem. Interfacial Electrochem., 57, 291 (1974).

12. A. Rigo, P. Viglino and G. Rotilio, Anal. Biochem., 68, 1 (1975).

13. T. Ikeda, O. Takemura and M. Senda, Abstracts of Papers, 29th Annual Meeting on Polarography, Nagaoka, 1983, Abstract 54.

14. T. Ikeda, O. Takemura and M. Senda, Abstracts of Papers, 30th Annual Meeting on Polarography, Hiroshima, 1984, Abstract 53.

15. O. Takemura, Thesis of Master Degree, Kyoto University, 1984.

16. J. Divišek and B. Kastening, J. Electroanal. Chem. Interfacial Electrochem., 65, 603 (1975).

17. S. Yamaguchi, T. Tsukamoto and M. Senda, Bunseki Kagaku, 35, 858 (1986).

18. J. Bannister, W. Bannister and E. Wood, Eur. J. Biochem., 18, 178 (1971).

19. J. Osteryoung and E. Kirowa-Eisner, Anal. Chem., 52, 62 (1980).

(Received June 15, 1989)

(Accepted July 1, 1989) 